\title{
Application of Fuzzy Control in a Photovoltaic Grid-Connected Inverter
}

\author{
Zhaohong Zheng, Tianxia Zhang, and Jiaxiang Xue $\mathbb{C}$ \\ School of Mechanical and Automotive Engineering, South China University of Technology, Guangzhou 510641, China \\ Correspondence should be addressed to Jiaxiang Xue; mejiaxue@scut.edu.cn
}

Received 27 August 2017; Revised 12 January 2018; Accepted 24 January 2018; Published 1 March 2018

Academic Editor: Andrea Bonfiglio

Copyright (C) 2018 Zhaohong Zheng et al. This is an open access article distributed under the Creative Commons Attribution License, which permits unrestricted use, distribution, and reproduction in any medium, provided the original work is properly cited.

\begin{abstract}
To realize the maximum power output of a grid-connected inverter, the MPPT (maximum power point tracking) control method is needed. The perturbation and observation $(\mathrm{P} \& \mathrm{O})$ method can cause the inverter operating point to oscillate near the maximum power. In this paper, the fuzzy control $\mathrm{P} \& \mathrm{O}$ method is proposed, and the fuzzy control algorithm is applied to the disturbance observation method. The simulation results of the $\mathrm{P} \& \mathrm{O}$ method with fuzzy control and the traditional P\&O method prove that not only can the new method reduce the power loss caused by inverter oscillation during maximum power point tracking, but also it has the advantage of speed. Inductive loads in the post-grid-connected stage cause grid-connected current distortion. A fuzzy control algorithm is added to the traditional deadbeat grid-connected control method to improve the quality of the system's grid-connected operation. The fuzzy deadbeat control method is verified by experiments, and the harmonic current of the grid-connected current is less than $3 \%$
\end{abstract}

\section{Introduction}

In view of the traditional photovoltaic grid-connected inverter system, light intensity can affect the output power of a photovoltaic solar array to a large extent. Therefore, maximum power point tracking (MPPT) is performed to improve the utilization efficiency of the photovoltaic array and ensure that it maintains maximum power output.

In the first stage of a grid-connected inverter, an MPPT control algorithm mainly includes the constant voltage method, the perturbation and observation $(\mathrm{P} \& \mathrm{O})$ method, and the conductance increment method. The advantages of simplicity, easy implementation, and rapid MPPT have helped the P\&O method to be widely used in an MPPT algorithm. However, the $\mathrm{P} \& \mathrm{O}$ method can easily produce continuous oscillation around the maximum power point; therefore, a nonlinear control method, named fuzzy control, is added based on the traditional P\&O method. Fuzzy control can simplify the system design and is particularly useful for a nonlinear, hysteretic, time-varying, and model-incomplete system owing to its excellent robust performance $[1,2]$. Bououden et al. added an ant-colony intelligent optimization algorithm to fuzzy control, which can not only deal with nonlinearity but also reduce the parameter randomization of the algorithm [3].

The control methods in the post-grid-connected stage of full bridge inversion include current instantaneous value control (PI control) algorithm, repetitive control algorithm, deadbeat algorithm, and proportion resonance algorithm. The PI control algorithm is widely used owing to its simplicity and easy implementation. However, these control algorithms can only address parts of the problem. For example, the deadbeat algorithm is widely used owing to its high-speed system response time. The system works steadily when its inverter output is combined with resistive loads, yet when the inductive or capacitive loads are connected to the inverter output of system, as well as when the system is suffering from outside interference, the current and voltage at the load end fail to maintain synchronization and the system lacks stability. Besides, the harmonic rates of current and voltage at both ends of the load increase simultaneously.

Based on analysis of the MPPT fuzzy control of the P\&O method in the first stage of a photovoltaic grid-connected inverter, this paper proposes a fuzzy control-based deadbeat 


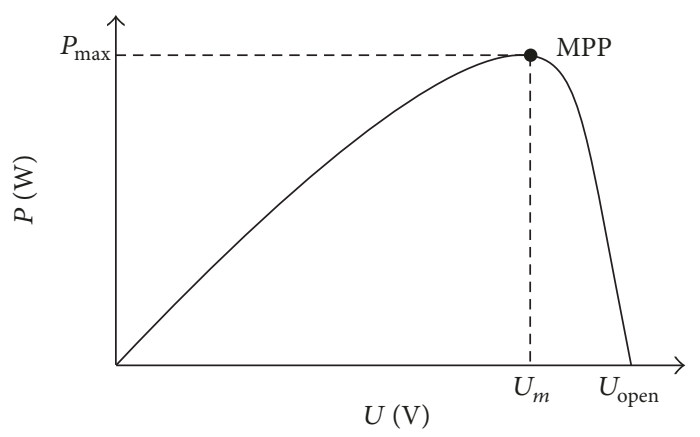

(a) Photovoltaic $P$ - $V$ curve

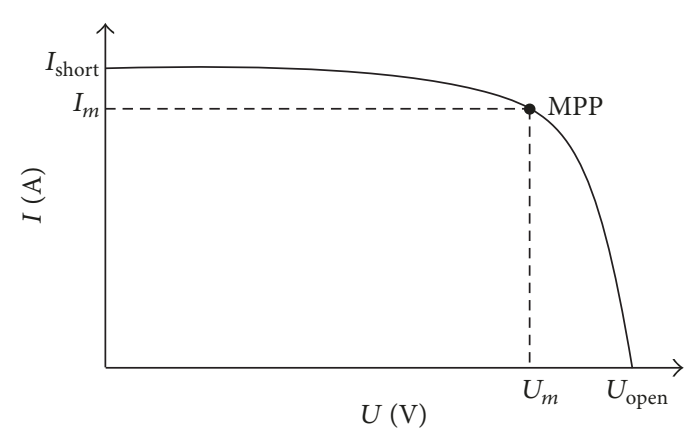

(b) Photovoltaic $I$ - $V$ curve

FIGURE 1: Output curve of photovoltaic solar array.

control strategy that can be used in the poststage of the photovoltaic grid-connected inverter, which can not only adapt to the nonlinear load but also reduce the harmonic waves of the inverter output.

\section{Design of MPPT Fuzzy Control Algorithm in the First Stage of the Photovoltaic Grid- Connected Inverter}

The MPPT of a photovoltaic array needs to be conducted to make the best use of the photovoltaic solar array. The $P-V$ and $I-V$ curves of a photovoltaic solar cell are shown in Figure 1. where $U_{\text {open }}$ indicates the open-circuit voltage of the photovoltaic solar panel and is also its maximum output voltage; $I_{\text {short }}$ indicates the short-circuit current of the photovoltaic solar panel and is also its maximum output current; $P_{\max }$ indicates the maximum output power of the photovoltaic solar panel in the present case; $I_{m}$ is the current at the maximum power point; and $U_{m}$ is the voltage at the maximum power point $[4,5]$.

2.1. MPPT Control Strategy of P\&O Method in the First GridConnected Stage. The first-stage MPPT control is conducted using the first-stage interleaving Boost circuit. The output voltage of the photovoltaic solar array used in this study is 200-350 V, and a bus voltage of approximately $400 \mathrm{~V}$ can be obtained using the booster circuit. The $\mathrm{P} \& \mathrm{O}$ method is used as the MPPT control method in this study. The disturbance voltages are continuously provided to the output end of the photovoltaic solar array, to calculate the output powers of the two photovoltaic arrays. The output powers are input to $\mathrm{PI}$ regulation to produce a pulse width modulation (PWM) control pulse. After passing through the drive circuit, the PWM signal can directly drive the switching element in the boost circuit in order to realize MPPT.

As the name suggests, the $\mathrm{P} \& \mathrm{O}$ method is used to continuously provide the disturbance voltage and calculate the output powers of the two photovoltaic arrays until they are operating around the maximum power point. The operating method is described as follows: " $\delta(n)$ " is used as the disturbed value of the photovoltaic arrays' output voltage. $\delta(n)=+\Delta V$ occurs when the perturbation direction is voltage-increasing, while $\delta(n)=-\Delta V$ occurs when the perturbation direction is voltage-decreasing. The output power $P(n)$ is calculated in accordance with the current and voltage values measured at the output end. In addition, a comparison is made between $P(n)$ and $P(n-1)$. The perturbation direction is correct in the case where $P(n)$ is greater than $P(n-1)$; thus, the perturbation should be continually applied to the photovoltaic array according to the original direction of perturbation voltage, which is $\delta(n)=\delta(n-1)$. The perturbation direction is wrong if the output power decreases; thus, $\delta(n)=-\delta(n-1)$ in the next perturbation. The adjustments should be performed unceasingly according to the perturbation method until the photovoltaic solar array is operating around the maximum power point $[6,7]$. The perturbation curve is shown in Figure 2 .

The software flow diagram of the $\mathrm{P} \& \mathrm{O}$ method described in this paper is shown in Figure 3. The current output power $P(n)$ of the solar panel is calculated according to the output voltage $V(n)$ and output current $I(n)$ of the solar photovoltaic array sampled by the system. Then, the output power $P(n)$ is subtracted from the last output power $P(n-$ $1)$. If the absolute value of the difference is less than or equal to the set value $\delta$, the output power is equal to the last output power and the system will produce no action output and return to the interrupt subprogram. The purpose here is to prevent the system misjudgments caused by the sampled signal fluctuation of the digital signal processor. If the absolute value of the difference is greater than $\delta$, a comparison between $P(n)$ and $P(n-1)$ is conducted. When $P(n)>P(n-1), V(n)>V(n-1)$, which proves that the perturbation direction is correct and the current operating point is adjustable. Thus, the reference value of voltage $V_{\text {ref }}(n)$ can be further increased. When $P(n)>P(n-1), V(n)<$ $V(n-1)$, which proves that the perturbation direction is correct and the current operating point is adjustable. Thus, the reference value of voltage $V_{\text {ref }}(n)$ can be further decreased. When $P(n)<P(n-1), V(n)>V(n-1)$, which implies that the perturbation direction is incorrect and the current operating point is located on the right side of the maximum power point. Thus, the direction should be changed and the reference value of voltage $V_{\text {ref }}(n)$ should be decreased as well. Yet when $P(n)<P(n-1), V(n)<V(n-1)$, which indicates that the perturbation direction is incorrect and the current operating point is adjustable. Thus, the direction should be 


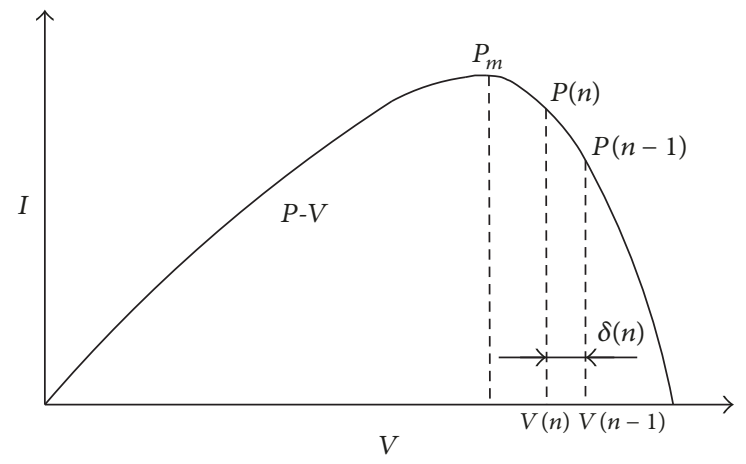

Figure 2: P\&O curve of solar array.

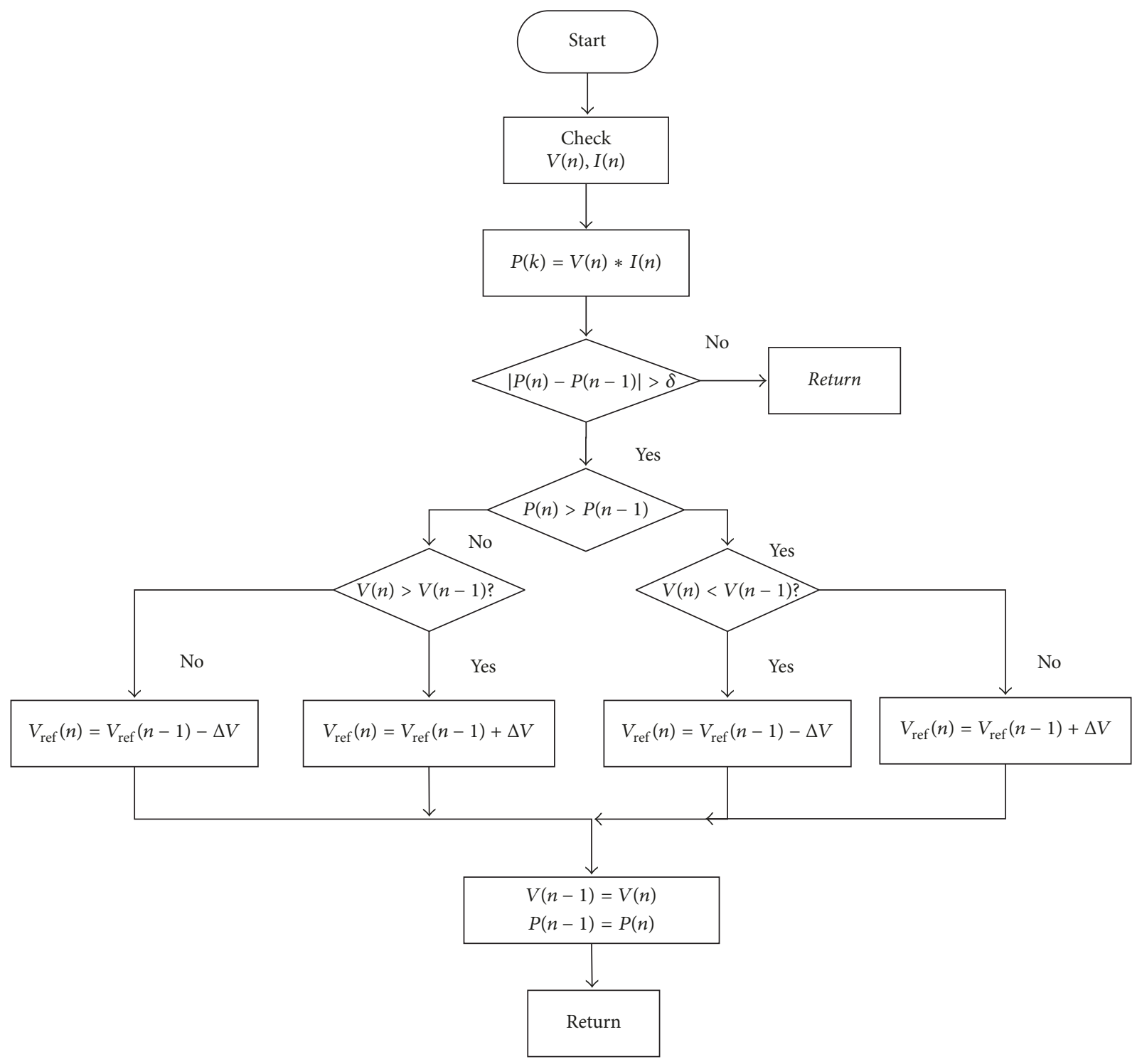

FIGURE 3: Control flow diagram of $\mathrm{P} \& \mathrm{O}$ method. 


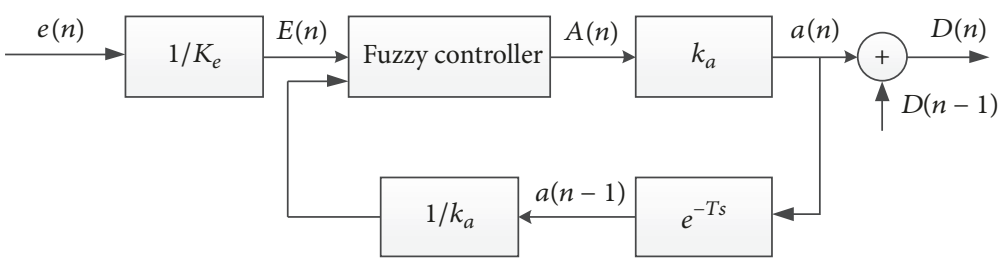

Figure 4: Fuzzy controller.

changed and the reference value of voltage $V_{\text {ref }}(n)$ should be increased [8].

2.2. Design of MPPT Fuzzy Control Based on P\&O Method. The step size of the traditional $\mathrm{P} \& \mathrm{O}$ method remains unchanged during the process of MPPT, while the fuzzycontrolled P\&O method actually improves the traditional $\mathrm{P} \& \mathrm{O}$ method with a fixed step. The control method can adjust the perturbation step according to the real-time output power of the photovoltaic solar cell to ensure that the operating point can be closer to the maximum power point. According to the principle of the $\mathrm{P} \& \mathrm{O}$ method, the output power of the solar cell is used as the objective function, while the duty ratio is used as the control variable. The current step size is adjusted and confirmed based on the variation in the power value and the duty ratio at the last moment. The input of the fuzzy controller at moment $n$ is the variation in the power value in the photovoltaic system at moment $n$ and the step size of the duty ratio $[9,10]$ at moment $n-1$, while the output at moment $n$ is the step size of the duty ratio at moment $n$. Thus, the fuzzy controller designing this study is as shown in Figure 4, where $k_{e}$ and $k_{a}$ are the quantization factors.

Input. $e(n)$ refers to the actual value of the difference between the output powers at moments $n$ and $n-1$, while $E(n)$ is the corresponding value of the difference in the universe of fuzzy sets. $a(n-1)$ refers to the actual value of the step size at moment $n-1$, while $A(n-1)$ is the corresponding value of the step size in the universe of fuzzy sets.

Output. $a(n)$ is the actual value of the step size at moment $n$, while $A(n)$ refers to the corresponding value of the step size in the universe of fuzzy sets.

The Mamdani controller is selected in the Matlab fuzzy box and the centroid method is used to solve fuzzification. The fuzzy linguistic variables $E$ and $A$ are defined as five and three subsets, respectively, which are $E=$ $\{\mathrm{NB}, \mathrm{NS}, \mathrm{ZE}, \mathrm{PS}, \mathrm{PB}\}$ and $A=\{\mathrm{N}, \mathrm{Z}, \mathrm{P}\}$. Here, NB, NS, Z, PS, and $\mathrm{PB}$ represent negative large, negative small, positive zero, positive small, and positive large, while $\mathrm{N}, \mathrm{P}$, and $\mathrm{Z}$ represent negative, positive, and zero fuzzy, respectively. The rule table of MPPT fuzzy control is shown in Table 1.

\section{Fuzzy Control Algorithm in the Post-Grid- Connected Stage of Full-Bridge Inversion}

Two control models of the poststage full-bridge inversion include controlling of output voltage and controlling of output current. The control strategy of the voltage control
TABLE 1: Rules of MPPT fuzzy control.

\begin{tabular}{lccccc}
\hline$E(n) / A(n-1)$ & $\mathrm{NB}$ & $\mathrm{NS}$ & $\mathrm{ZE}$ & $\mathrm{PS}$ & $\mathrm{PB}$ \\
\hline $\mathrm{N}$ & $\mathrm{PB}$ & $\mathrm{PM}$ & $\mathrm{NS}$ & $\mathrm{PM}$ & $\mathrm{NB}$ \\
$\mathrm{Z}$ & $\mathrm{NM}$ & $\mathrm{NS}$ & $\mathrm{ZE}$ & $\mathrm{PS}$ & $\mathrm{PM}$ \\
$\mathrm{P}$ & $\mathrm{NB}$ & $\mathrm{NM}$ & $\mathrm{PS}$ & $\mathrm{PM}$ & $\mathrm{PB}$ \\
\hline
\end{tabular}

mode is to consider the entire system as a controlled voltage source and make the inverter output voltage a system control quantity; the control strategy of the current control mode is to consider the entire system as a controlled current source and make the inverter output current a system control quantity.

The control mode of the output voltage is equivalent to a controlled voltage source; therefore, it is easily affected by the power grid voltage. The quality of the inverter output voltage is significantly impacted if the power grid voltage suffers from any abnormality. However, for the control mode of the output current, the controlled output quantity is the inverter output current and the current source is highly resistive to the voltage source; thus, the quality of the output current cannot suffer any impact from the power grid voltage. In short, the control mode of the output current should be used in the gridconnected operation mode, which can improve the quality of the output power as well.

The grid-connected operation mode generally adopts the double closed-loop control algorithm with an outer loop of bus voltage and inner loop of current output. In this paper, a fuzzy control algorithm is added to the PI modulation of the bus-voltage outer ring and the parameters of bus voltage loop are adjusted constantly to make the closed-loop control more precise. Besides, the output quantity of the outer voltage loop is one-unit current. The inner loop of the double closed loop is a current loop, which adopts the deadbeat control algorithm to ensure the synchronization between the output current and power grid voltage.

\subsection{Design of Deadbeat Algorithm in the Post-Grid-Connected} Stage. The poststage inverter output of the grid-connected operation mode adopts the output current control. The deadbeat control method based on the output current control is used in the grid-connected inverter system described in this paper. The control system is realized using a digital signal processor, which exhibits highly precise AD sampling and rapid internal operation, which is suitable for the deadbeat control.

When the inverter is operating in the grid-connected mode, the poststage inverter circuit is equivalent to the circuit 


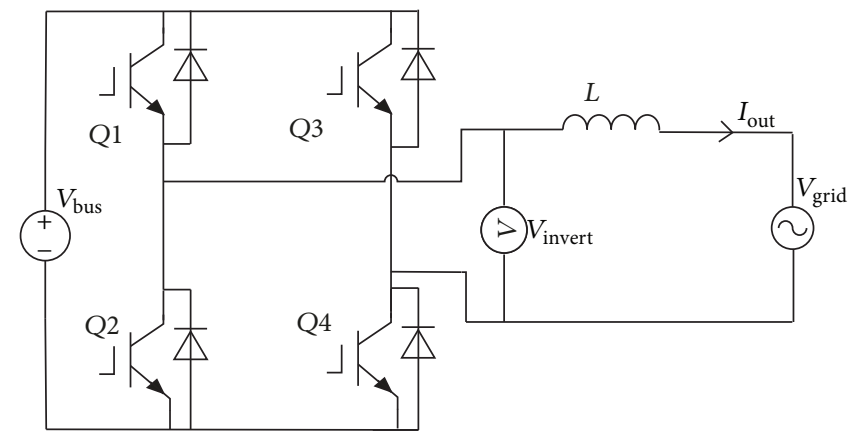

FIGURE 5: Schematic of poststage grid-connected inverter circuit.

diagram shown in Figure 5. The current of the filtering capacitance at the output end and the losses in the circuit should be neglected. The complete bridge is composed of Q1-Q4, where Q1 and Q4 perform the turn-on operations alternatively, while $Q 2$ and $Q 3$ perform the turn-off operations alternatively to transfer power to the grid. $L$ is the filter inductance at the output end, while $V_{\text {bus }}$ is the DC bus voltage generated by the first-stage interleaving boost circuit and should be stabilized at about $420 \mathrm{~V}$ by the control strategy of a poststage full-bridge inverter. $I_{\text {invert }}$ is the inverter output current, $V_{\text {invert }}$ is the inverter output voltage, and $V_{\text {grid }}$ is the power grid voltage.

The following equation can be obtained according to the output inductance characteristics:

$$
L \frac{d I_{\text {out }}}{d t}=V_{\text {invert }}-V_{\text {grid }}
$$

The above equation can be transformed into the following equation within one control cycle $T$ of the switch tube:

$$
V_{\text {inver-ave }}(n)=V_{\text {grid-ave }}(n)+L \frac{I_{\text {out }}(n+1)-I_{\text {out }}(n)}{T},
$$

where $L$ is the filter inductance at the inverter output end; $T$ is the control cycle of the switch tube; the average value of the voltage at the inverter output end sampled during $n$ sampling period is $V_{\text {inver-ave }}(n)$; the average value of the power grid voltage during $n$ sampling period is $V_{\text {grid-ave }}(n)$; the inverter output current sampled during $n$ sampling period is $I_{\text {out }}(n)$; the inverter output current sampled during $(n+1)$ sampling period is $I_{\text {out }}(n+1) ; I_{\text {ref }}(n+1)$ is used to replace $I_{\text {out }}(n+1)$ in (2) so as to ensure that the current passing through the filter inductance can track the reference current of the inverter output $I_{\text {ref }}(n+1)$. Then,

$$
V_{\text {inver-ave }}(n)=V_{\text {grid-ave }}(n)+L \frac{I_{\text {ref }}(n+1)-I_{\text {out }}(n)}{T} .
$$

The average value of the power grid voltage $V_{\text {grid-ave }}(n)$ can be replaced with

$$
\begin{aligned}
V_{\text {grid-ave }}(n) & =\frac{V_{\text {grid }}(n+1)+V_{\text {grid }}(n)}{2} \\
V_{\text {grid }}(n+1)-V_{\text {grid }}(n) & =V_{\text {grid }}(n)-V_{\text {grid }}(n-1) .
\end{aligned}
$$

From (4),

$$
V_{\text {grid-ave }}(n)=1.5 V_{\text {grid }}(n)-V_{\text {grid }}(n-1) .
$$

From (3) and (5),

$$
\begin{aligned}
V_{\text {inver-ave }}(n)= & 1.5 V_{\text {grid }}(n)-V_{\text {grid }}(n-1) \\
& +L \frac{I_{\text {ref }}(n+1)-I_{\text {out }}(n)}{T} .
\end{aligned}
$$

The poststage inverter output voltage of the gridconnected inverter is directly proportional to the first-stage DC bus voltage; thus, the duty ratio of the high-frequency tube during the control cycle is

$$
\begin{aligned}
& D(n)=\frac{V_{\text {invert-ave }}}{V_{\text {bus }}} \\
& =\frac{1.5 V_{\text {grid }}(n)-V_{\text {grid }}(n-1)+L\left(\left(I_{\text {ref }}(n+1)-I_{\text {out }}(n)\right) / T\right)}{V_{\text {bus }}},
\end{aligned}
$$

where $I_{\text {ref }}(n+1)$ is a given reference signal of current at the $(n+1)$ cycle obtained by the combined effect of both PI voltage modulation and poststage phase-locked loop control during the process of full bridge inversion.

$V_{\text {bus }}$ is the DC bus voltage, while $V_{\text {grid }}(n)$ and $I_{\text {out }}(n)$, respectively, are the effective values of power grid voltage and inverter output current sampled during the current cycle. The effective values of power grid voltage and inverter output current sampled during the last cycle can be expressed as $V_{\text {grid }}(n-1)$. Therefore, the duty ratio of switch tube $D$ can be obtained through (7) to realize the deadbeat control over the entire circuit. According to (7), the control of the duty ratio of the switch tube can be used to regulate the reference current $I_{\text {ref }}(n+1)$. However, the reference signal of the current should maintain its pace with the power grid voltage signal.

\subsection{Design of Grid-Connected Fuzzy Control Algorithm Based} on Deadbeat Algorithm. The system works steadily when its inverter output is combined with resistive loads, yet when the inductive or capacitive loads are connected to the inverter output of the system, as well as when the system is suffering from outside interference, the current and voltage at the load end fail to maintain synchronization and the system lacks stability. Besides, the harmonic rate of current and voltage 


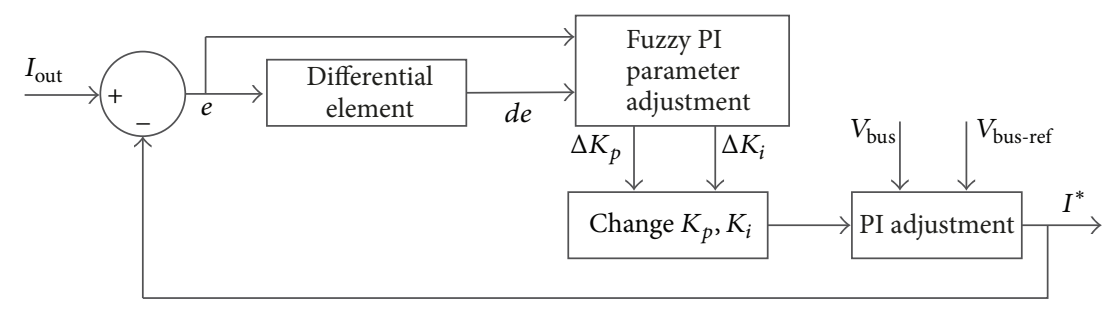

Figure 6: Fuzzy controller.

TABLE 2: Rule table of $K i$ parameter fuzzy control.

\begin{tabular}{llllllll}
\hline$\Delta E / E$ & NB & NE & NS & ZO & PS & PE & PB \\
\hline NB & PB & PB & PB & PB & PE & PS & ZO \\
NE & PB & PB & PB & PE & PS & ZO & NS \\
NS & PB & PB & PE & PS & ZO & NS & NE \\
ZO & PB & PE & PS & ZO & NS & NE & NB \\
PS & PE & PS & ZO & NS & NE & NB & NB \\
PE & PS & ZO & NS & NE & NB & NB & NB \\
PB & ZO & NS & NE & NB & NB & NB & NB \\
\hline
\end{tabular}

TABLE 3: Rule table of $K p$ parameter fuzzy control.

\begin{tabular}{llllllll}
\hline$\Delta E / E$ & $\mathrm{NB}$ & $\mathrm{NE}$ & $\mathrm{NS}$ & ZO & PS & PE & PB \\
\hline NB & NB & NB & NB & NB & NE & NS & ZO \\
NE & NB & NB & NB & NE & NS & ZO & PS \\
NS & NB & NB & NE & NS & ZO & PS & PE \\
ZO & NB & NE & NS & ZO & PS & PE & PB \\
PS & NE & NS & ZO & PS & PE & PB & PB \\
PE & NS & ZO & PS & PE & PB & PB & PB \\
PB & ZO & PS & PE & PB & PB & PB & PB \\
\hline
\end{tabular}

at both ends of the load increases simultaneously. Similar problems exist in the mutual switchover of grid-off and gridconnected operating modes. Owing to the characteristics of fuzzy control, the fuzzy control method can be added to the original unipolar deadbeat control method to improve the stability of the inverter system when the nonlinear load is connected to the output end of the load. Fuzzy control is mainly introduced into the photovoltaic control system to properly modify the PI control parameters, $K p$ and $K i$, which can eventually improve the system stability. The fuzzy controller should be added to the full bridge inverter control to effectively fortify the power factor $[11,12]$ during the gridconnected process of the inverter.

$e(k)$ and $\Delta e(k)$ are the two inputs of a fuzzy controller, where $e(k)$ refers to the error in the fuzzy controller and $\Delta e(k)$ is the error rate. Their relation can be expressed as

$$
\begin{aligned}
e(k) & =e(k)-e(k-1) \\
\Delta e(k) & =\frac{d e(k)}{d t}=\frac{e(k)-e(k-1)}{t(k)-t(k-1)} .
\end{aligned}
$$

The double inputs designed in the paper are the current error $i_{e}$ and the change rate of current error $d i_{e} / d t$, generated by the combined effect of the actual current at the sampling output end and the predictive current in the next cycle, while the double outputs are $\Delta K p$ and $\Delta K i[13]$, which are the manipulating variables of $K p$ and $K i$ in PI modulation. The fuzzy controller designed for the closed-loop PI modulation of the first-stage bus voltage in the grid-connected system is shown in Figure 6.

The following seven fuzzy variables are added to the fuzzy set: positive large, positive relatively large, positive relatively small, zero, negative relatively small, negative relatively large, and negative large, which are represented as $\mathrm{PB}, \mathrm{PE}, \mathrm{PS}, \mathrm{ZO}$, NS, NE, and NB, respectively.

The program preparation is conducted based on the rule table of fuzzy control, as shown in Tables 2 and 3.

The control strategy chart for the poststage full-bridge inversion of the photovoltaic grid-connected inverter is shown in Figure 7. A comparison between the sampled DC bus voltage $V_{\text {bus }}$ and the reference value $V_{\text {bus-ref }}$ set in the system is performed via PI modulation. The fuzzy control algorithm is continuously used to adjust $K p$ and $K i$ in PI modulation, and the given amplitude of the gridconnected current can be obtained after the controlling operation of PI. The power grid voltage is captured at this 


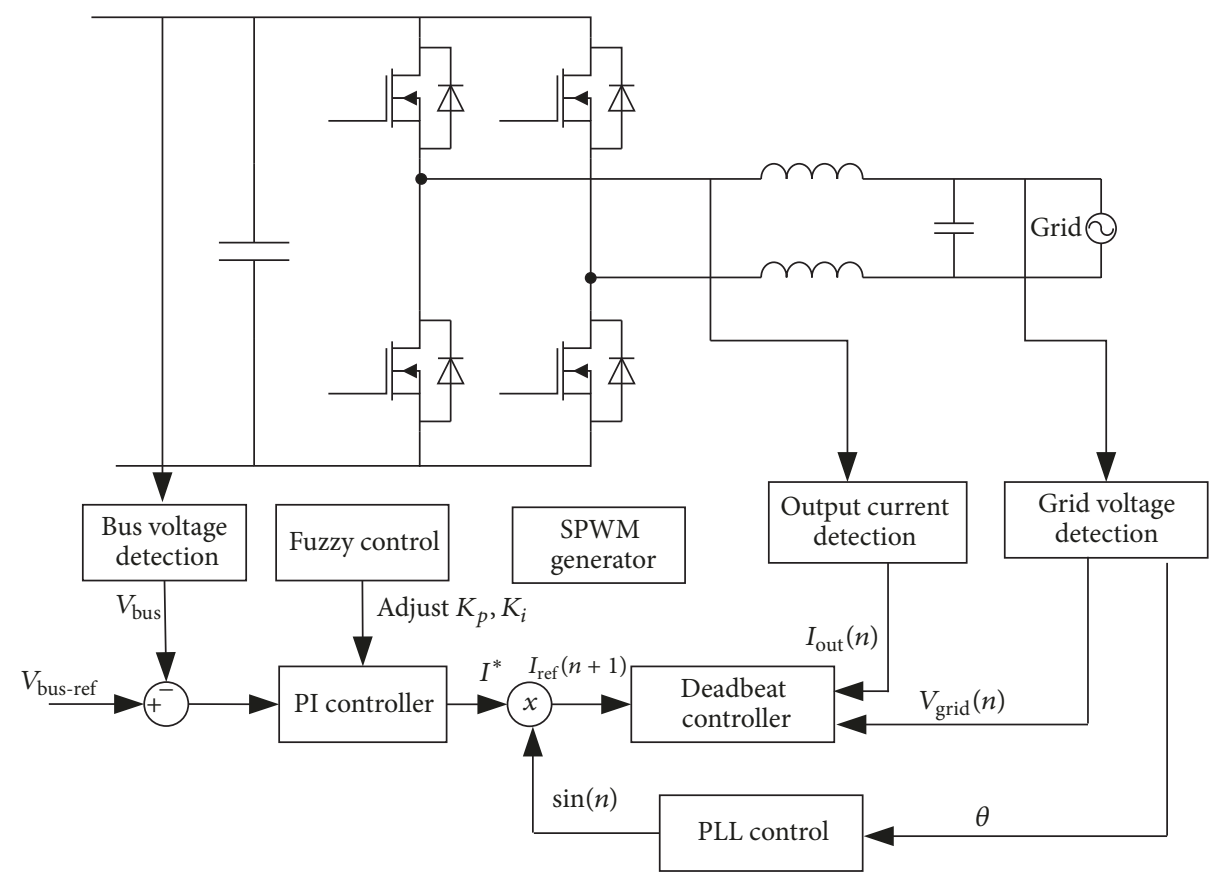

FIGURE 7: Control strategy chart for poststage inversion of grid-connected operating mode.

moment. If the rising edge of the square wave is detected, the capture accessing the digital signal processor is interrupted to generate a unit sinusoidal current signal that is in sync with the power grid voltage. The predicted value of current $I_{\text {ref }}(n+1)$ in the next cycle can be obtained by multiplying the amplitudes of current signal $I^{*}$ and the sinusoidal signal. Finally, the predicted value of current $I_{\text {ref }}(n+1)$ in the next cycle, the effective value of current $I_{\text {out }}(n)$ at the inverting output end, the effective value of power grid voltage $V_{\text {grid }}(n)$ sampled in the current cycle, the effective value of power grid voltage $V_{\text {grid }}(n-1)$ sampled in the last cycle, and the effective value of DC bus voltage $V_{\text {bus }}$ are inputted into the deadbeat controller to output the PWM signal. After passing through the amplifying and isolating circuits, the square signal can drive the switch tube to produce a current with the same frequency and phase as those of the grid voltage.

\section{Simulation and Analysis of Experimental Results}

4.1. MPPT Simulation of First-Stage Fuzzy P\&O Method. The light intensity of the photovoltaic array is $G=1000 \mathrm{~W} / \mathrm{m}^{2}$, the ambient temperature is $T=25^{\circ} \mathrm{C}$, the maximum power is $P=270 \mathrm{~W}$, the voltage of the maximum power point is $V_{\mathrm{mpp}}=70 \mathrm{~V}$, the voltage of the open circuit is $V_{\mathrm{OC}}=100 \mathrm{~V}$, the current of the short circuit is $I_{\mathrm{SC}}=5 \mathrm{~A}$, and the current of the maximum power point is $I_{\mathrm{mpp}}=3.8 \mathrm{~A}$. The design power of the boost circuit is $1500 \mathrm{~W}, C 1=C 2=1000 \mu \mathrm{F}, L$ $=2.0 \mathrm{mH}, R=592 \Omega$, and the operating frequency is $20 \mathrm{kHz}$. The fuzzy MPPT model is formulated as shown in Figure 8, the power tracking diagram of the simulation output is shown in Figure 9, and the voltage tracking diagram is shown in Figure 10. Thus, the duration of MPPT is shortened to $0.04 \mathrm{~s}$ after adopting the fuzzy control, which is faster than the traditional perturbation method.

4.2. Experiment Design of Poststage Full-Bridge Inverting Fuzzy Deadbeat. When the output end is composed of loads with different characteristics, the load characteristics can be allocated via an electronic load device and the loads can be resistive, capacitive, inductive, or mixed. The introduction of a fuzzy control algorithm can significantly improve the quality of the grid-connected output current, especially if the output load is not a pure resistant one; the output waveform of the grid-connected output current appears much smoother than that of the current in the original unipolar algorithm, and there is lesser clutter. Meanwhile, the current at the load end is much smoother. The waveforms of the output current and voltage under the grid-connected operating mode are shown in Figure 11, where the first channel is the current at the load end, the second channel is the grid-connected output current, and the third channel is the power grid voltage.

The loads of (a) and (b) and those of (c) and (d) in Figure 11 are the same. (a) and (c) adopt the conventional deadbeat method, while (b) and (d) show the waveform figures of deadbeat control method after the introduction of the fuzzy control algorithm. According to (b) and (d), the waveforms of the grid-connected output current and load current are somewhat smoother and the harmonic wave is shortened.

\section{Conclusions}

In this study, modeling analysis is conducted for the MPPT of fuzzy control-based P\&O method in the first stage of photovoltaic grid connection in Matlab/Simulink. The MPPT 


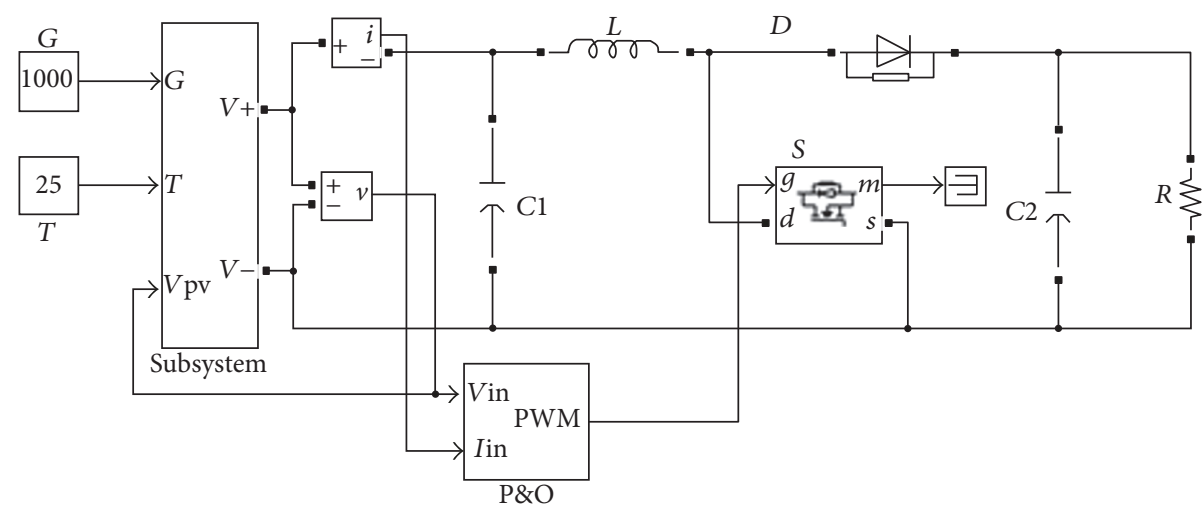

Figure 8: Model of fuzzy MPPT control.

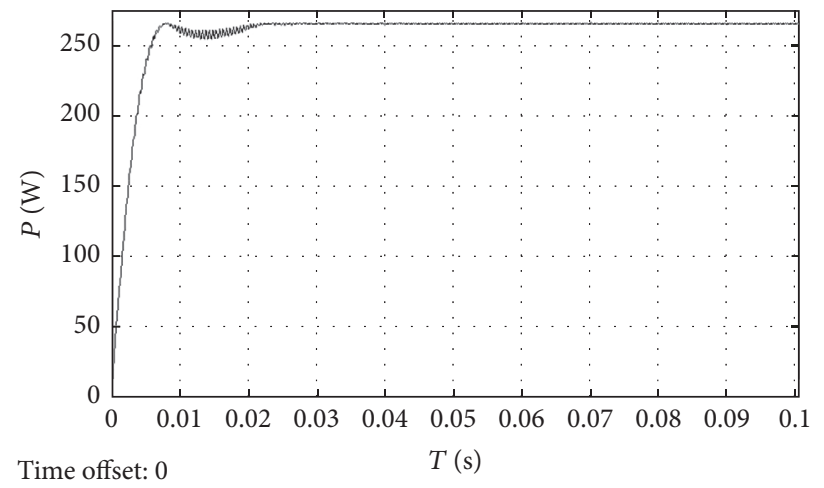

FIGURE 9: Output power of photovoltaic array.

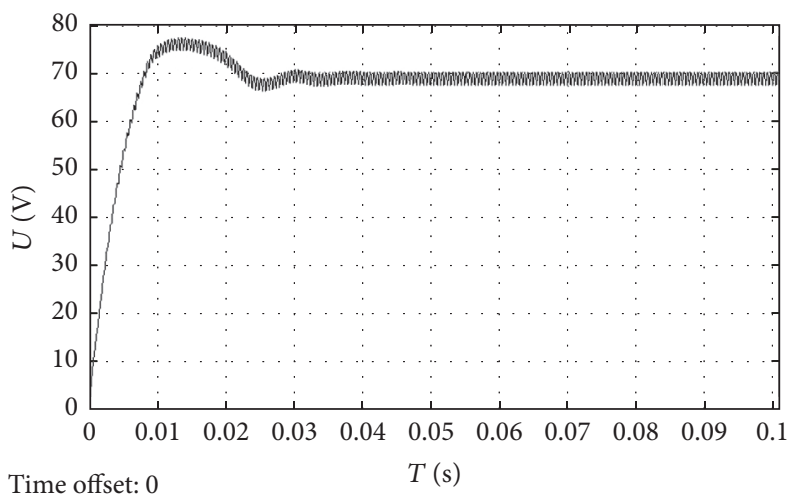

FIGURE 10: Output voltage of photovoltaic array.

of fuzzy control-based P\&O method and that of traditional $\mathrm{P} \& \mathrm{O}$ method are analyzed thoroughly by the simulation comparison. According to the simulation results, the MPPT of fuzzy control-based $\mathrm{P} \& \mathrm{O}$ method exhibits rapid response and small steady-state oscillation, which can effectively make up for the shortcomings of the traditional P\&O method, improve system efficiency, and reduce power losses to an extreme. In addition, the fuzzy control algorithm is added to the full bridge inversion of the post-grid-connected stage, and the experiment is performed in the formulated experimental platform. Loads with different characteristics are added to the output end of the post-grid-connected stage in order to compare the conventional deadbeat control method and the fuzzy control-based deadbeat control method. The results show that the fuzzy control-based deadbeat control method can enhance the robustness and reduce the harmonic wave when the system relates to nonlinear load. 


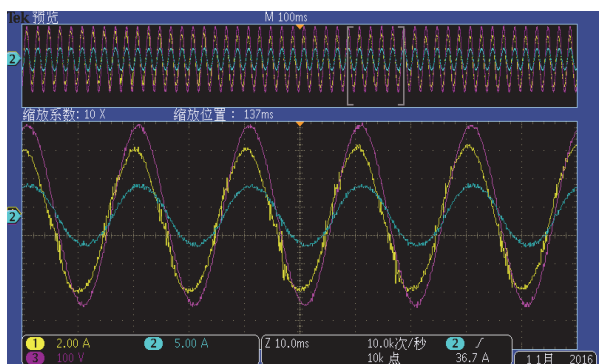

(a) Waveform of conventional deadbeat control with $500 \mathrm{~W}$ resistive load $+300 \mathrm{~W}$ capacitive load

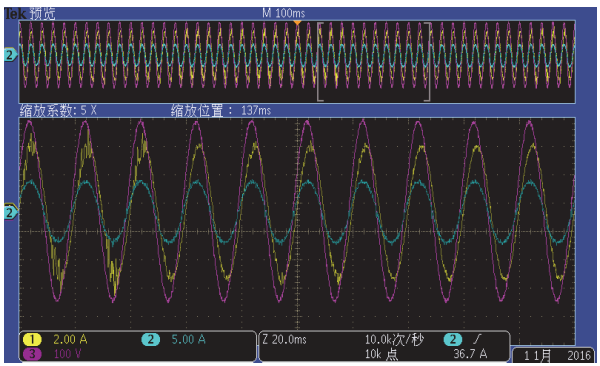

(c) Waveform of conventional deadbeat control with $100 \mathrm{~W}$ capacitive load $+150 \mathrm{~W}$ inductive load $+500 \mathrm{~W}$ resistive load

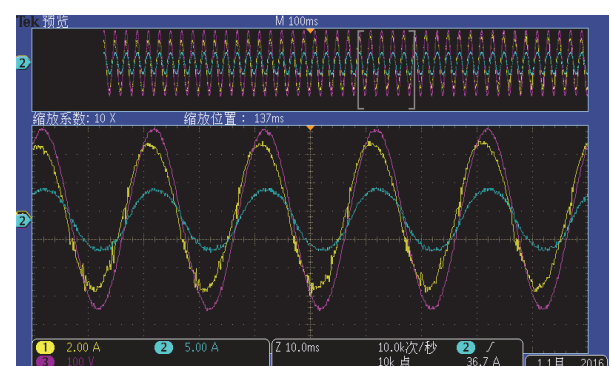

(b) Waveform of fuzzy control method with $500 \mathrm{~W}$ resistive load $+300 \mathrm{~W}$ capacitive load

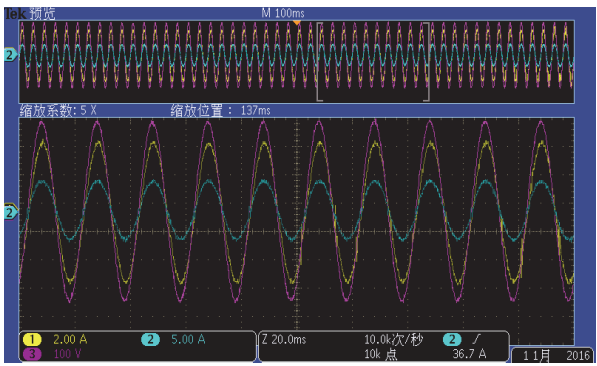

(d) Waveform of fuzzy control method with $100 \mathrm{~W}$ capacitive load $+150 \mathrm{~W}$ inductive load $+500 \mathrm{~W}$ resistive load

FIGURE 11: Grid-connected output current and load current with different load characteristics.

\section{Conflicts of Interest}

The authors declare that there are no conflicts of interest regarding the publication of this paper.

\section{Acknowledgments}

The authors acknowledge financial support for this research from: Third Batch Innovative Research Team Introduction Program of Dongguan City in 2015 (2017360004004), Special Funding of Collaborative Innovation and Platform Circumstance Construction of Guangdong Province (2016B090918067), and Industry-University-Research of Dongcheng District, Dongguan City, in 2015; Natural Science Foundation of Guangdong Province (2015A030313675).

\section{References}

[1] S. Bououden, M. Chadli, S. Filali, and A. El Hajjaji, "Fuzzy model based multivariable predictive control of a variable speed wind turbine: LMI approach," Journal of Renewable Energy, vol. 37, no. 1, pp. 434-439, 2012.

[2] H. Dahmani, M. Chadli, A. Rabhi, and A. El Hajjaji, "Road curvature estimation for vehicle lane departure detection using a robust Takagi-Sugeno fuzzy observer," Vehicle System Dynamics, vol. 51, no. 5, pp. 581-599, 2013.

[3] S. Bououden, M. Chadli, and H. R. Karimi, "An ant colony optimization-based fuzzy predictive control approach for nonlinear processes," Information Sciences, vol. 299, pp. 143-158, 2015.
[4] M. Görig and C. Breyer, "Energy learning curves of PV systems," Environmental Progress \& Sustainable Energy, vol. 35, no. 3, pp. 914-923, 2016.

[5] E. D. Aranda, J. A. Gómez Galan, M. S. de Cardona, and J. M. Andújar Márquez, "Measuring the I-V curve of PV generators: Analyzing different dc-dc converter topologies," IEEE Industrial Electronics Magazine, vol. 3, no. 3, pp. 4-14, 2009.

[6] P. Manimekalai, R. Harikumar, and S. Raghavan, "A hybrid maximum power point tracking (MPPT) with interleaved converter for standalone photo voltaic (PV) power generation system," Annual Review of Microbiology, vol. 60, no. 3, pp. 451475, 2014.

[7] D. Sharma K and G. Purohit, "Advanced perturbation and observation (PO) based maximum power point tracking (MPPT) of a solar photo-voltaic system[C]," in Proceedings of the IEEE India International Conference on Power Electronics, $\mathrm{p}$. $1,2012$.

[8] A. Al Nabulsi and R. Dhaouadi, "Efficiency optimization of a dsp-based standalone PV system using fuzzy logic and dualMPPT control," IEEE Transactions on Industrial Informatics, vol. 8, no. 3, pp. 573-584, 2012.

[9] Y.-T. Chen, Y.-C. Jhang, and R.-H. Liang, "A fuzzy-logic based auto-scaling variable step-size MPPT method for PV systems," Solar Energy, vol. 126, pp. 53-63, 2016.

[10] M. Abdourraziq A, M. Ouassaid, and M. Maaroufi, "A fuzzy logic MPPT for photovoltaic systems using single sensor," in Proceedings of the Renewable and Sustainable Energy Conference, pp. 52-56, IEEE, 2015.

[11] G.-R. Yu, J.-J. Lai, and J.-Y. Liu, "T-S fuzzy control of a single-phase bidirectional inverter," in Proceedings of the IEEE 
International Conference on Industrial Technology, ICIT 2016, pp. 1462-1467, IEEE, March 2016.

[12] A. Tomova, M. Antchev, M. Petkova, and H. Antchev, "Fuzzy logic hysteresis control of a single-phase on-grid inverter: Computer investigation," International Journal of Power Electronics and Drive Systems, vol. 3, no. 2, pp. 179-184, 2013.

[13] L. K. Letting, J. L. Munda, and Y. Hamam, "Optimization of a fuzzy logic controller for PV grid inverter control using Sfunction based PSO," Solar Energy, vol. 86, no. 6, pp. 1689-1700, 2012. 


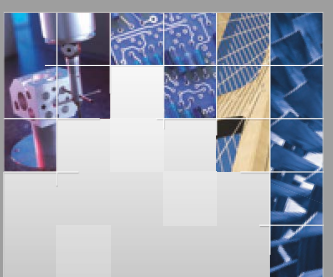

\section{Enfincering}
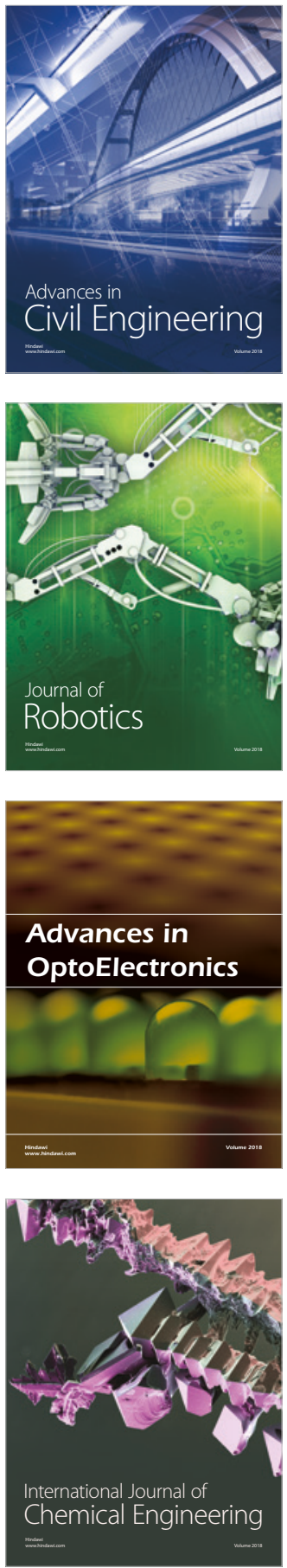

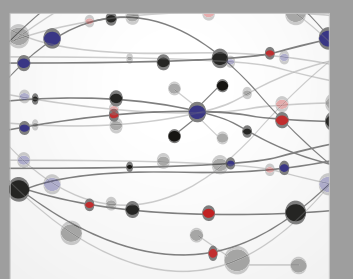

\section{Rotating \\ Machinery}

The Scientific World Journal

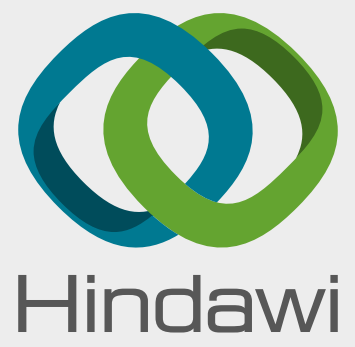

Submit your manuscripts at

www.hindawi.com
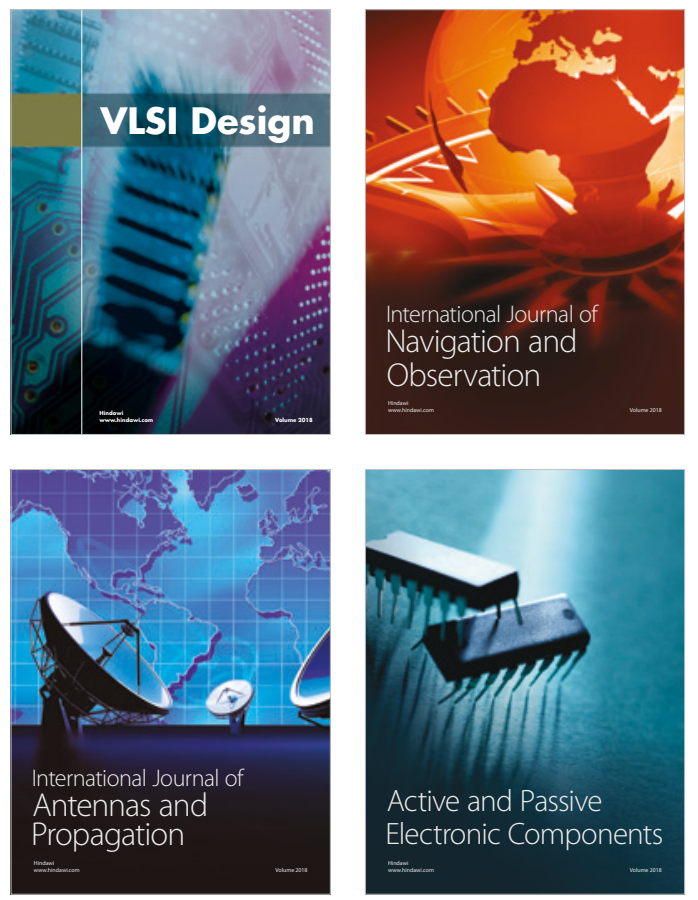
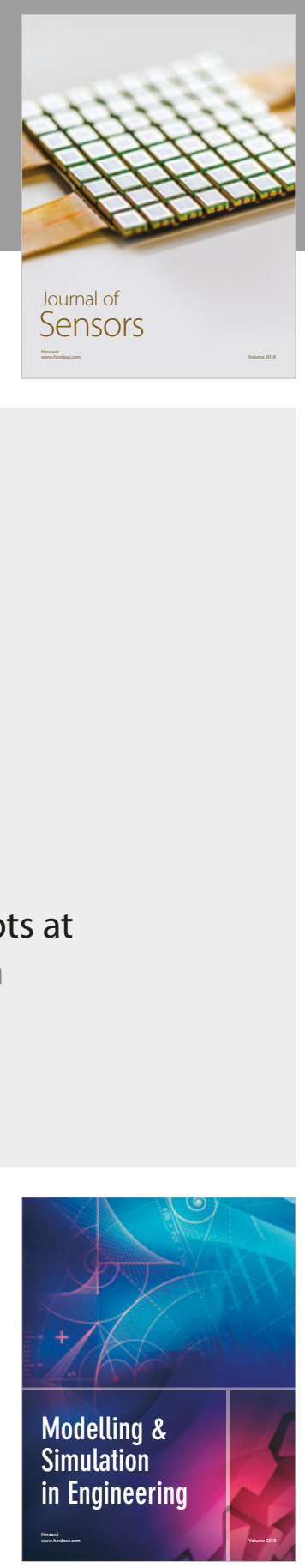

\section{Advances \\ Multimedia}
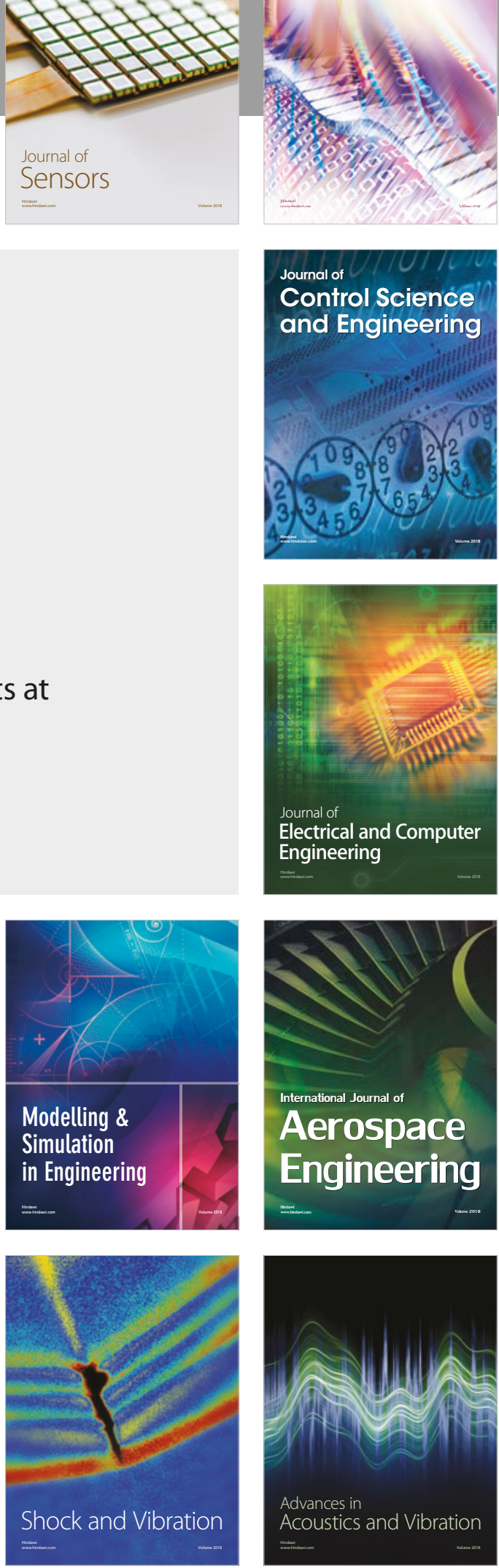